\title{
Estudos de caso na internacionalização varejista: uma revisão de literatura
}

\author{
Renata Maria de Almeida Bastos Gomes ${ }^{1 \mathrm{~A}}$, \\ Jorge Manoel Teixeira Carneiro ${ }^{B}$, Clarice Secches Kogut $^{C}$
}

APontifícia Universidade Católica do Rio de Janeiro - Instituto de Administração e Gerência, PUC-Rio/IAG, Rio de Janeiro, RJ, Brasil

${ }^{\mathrm{B}}$ Fundação Getúlio Vargas/Escola de Administração de Empresas de São Paulo, FGV-SP/EAESP, São Paulo, SP, Brasil

${ }^{C}$ Universidade Federal do Rio de Janeiro - Instituto Coppead de Administração, UFRJ/Coppead, Rio de Janeiro, RJ, Brasil

\section{DETALHES DO ARTIGO}

\section{Histórico do artigo:}

Recebido em 02 de outubro de 2015

Aceito em 20 de janeiro 2017

Disponível online em 30 de abril de 2017

Sistema de Revisão "Double Blind Review"

Editor científico:

Ilan Avrichir

\section{Palavras-chaves:}

Internacionalização de Varejo

Estudo de Caso

Revisão de Literatura

\begin{abstract}
RESUMO
A pesquisa em internacionalização varejista (IV) passou por intensa fase de desenvolvimento desde a década de 1990, dominada por pesquisas de natureza quantitativa e com base na experiência de varejistas de grandes formatos, como supermercados. Entretanto, a internacionalização do setor varejista evoluiu em bases que os modelos existentes não têm sido capazes de explicar, gerando uma demanda por pesquisas com métodos mais profundos de conhecimento. O resultado foi um aumento de artigos publicados desde o início da década de 2000 baseados pesquisas de natureza exploratória e qualitativa, como estudos de caso. Neste artigo, são identificadas principais contribuições no conhecimento sobre IV oriundas de estudos de caso, resultantes da seleção e análise de 48 artigos publicados em periódicos acadêmicos entre 2000 e 2015. Como resultado, são aqui apresentadas relevantes achados sobre etapas do processo de IV, tais como modo de entrada por franquia e desinvestimento internacional, e características do processo de IV de tipos específicos de firmas, tais como varejistas de moda e pequenas e médias varejistas.
\end{abstract}

(C) 2017 Internext | ESPM. Todos os direitos reservados.

\section{Introdução}

Os estudos sobre internacionalização varejista (IV) começaram a surgir na década de 1990, marcando o início de uma prolífica fase de desenvolvimento do conhecimento e consolidação da pesquisa que hoje conta com corpo teórico próprio (Alexander \& Doherty, 2010). Enquanto que parte do conhecimento sobre IV é oriunda dos conceitos de negócios internacionais, fortemente alicerçados na atividade manufatureira, outra parte é proveniente de pesquisas específicas para a atividade varejista, cujas especificidades demandam, segundo alguns autores, o desenvolvimento de corpo teórico próprio (Alexander \& Myers, 2000; Dawson, 1994, 2000).

\footnotetext{
${ }^{1}$ Contato do autor: renatamariagomes@uol.com.br
}

A pesquisa em IV passou por intensa fase de desenvolvimento nos últimos 20 anos, dominada por pesquisas quantitativas (Swoboda, Zentes, \& Elsner, 2009), em linha com o observado no campo de estudos em negócios internacionais (Welch, Piekkari, Plakoyiannaki, \& Paavilainen-Mäntymäki, 2011). Porém, vários autores defendem que a aplicação de métodos qualitativos, tais como estudos de caso (EC), é fundamental para o conhecimento de características idiossincráticas de culturas e países e na exploração de assuntos específicos, tais como processos de desinvestimento, instâncias de um mesmo fenômeno ocorrendo em vários países, e características de países emergentes (Elg, Ghauri, \& Tarnovskaya, 2008; Ghauri, 2004; Jonsson \& Foss, 2011). ECS são também considerados adequados para estudos sobre atividades varejistas e serviços 
internacionais, haja vista o alto grau de dependência que essas atividades têm do contexto (Palmer \& Owens, 2006).

Interessante notar que, não obstante a evidente e crescente abertura de lojas monomarca de inúmeras marcas internacionais de vários setores, como moda e luxo, no cenário varejista dos países, inclusive emergentes (Delloite, 2014), os estudos em IV são ainda fortemente concentrados em varejistas de grandes formatos, como supermercados e lojas de departamentos (Gomes, 2016). Portanto, pouco ainda se sabe sobre a IV de firmas cuja principal atividade é o desenvolvimento de marcas próprias.

Como resultado das peculiaridades da IV, há uma demanda na academia por pesquisas com métodos mais profundos de conhecimento (Alexander \& Doherty, 2010; Moore, Doherty, Alexander, \& Carpenter, 2010; Picot-Coupey, 2006) e com isso nota-se um aumento no número de artigos em IV publicados a partir da década de 2000 baseados em pesquisas de natureza exploratória e qualitativa (Alexander \& Doherty, 2010), tais como EC.

O presente artigo tem por objetivo identificar as principais contribuições de pesquisas que utilizaram o método de EC no conhecimento sobre IV, por meio de uma revisão sistemática da literatura acadêmica disponível entre os anos de 2000 e 2015. Na ótica acadêmica, os resultados deste artigo geram um ponto de partida para acadêmicos interessados em IV identificando lacunas na literatura relevantes neste campo. Do ponto de vista gerencial, este artigo identifica uma seleção criteriosa de EC em IV cujos aprendizados e conclusões constituem valiosa fonte de conhecimento para o corpo gerencial das empresas.

O artigo é iniciado por meio de uma breve revisão da evolução da literatura de IV, seguida da metodologia adotada na busca e identificação dos EC selecionados. Em seguida, os resultados da amostra selecionada, organizados por tema componente da IV, são apresentados discutidos. Ao final, conclui-se este artigo com as contribuições relevantes e as lacunas identificadas.

\section{Revisão de literatura}

A literatura de negócios internacionais vem buscando explicar os fenômenos envolvidos nos processos de internacionalização das firmas, com claro enfoque em manufatura (Dawson, 1994). Entretanto, para alguns autores, as bases teóricas da área de negócios internacionais não ofereciam modelos adequados para compreensão das estratégias de IV - tais como abrangência geográfica, modo de entrada e padrões de adaptação aos países de destino -e, por isso basearam seus estudos em achados empíricos e com fundamentação teórica oriunda dos estudos sobre o varejo (Alexander, 1990; Salmon \& Tordjman, 1989; Treadgold, 1991).

Dawson (1994) alertou que o campo de negócios internacionais foi desenvolvido com base em firmas manufatureiras e que adaptações de conceitos vindos da manufatura para o varejo deveriam ser feitas com certo cuidado, pois há vários fatores que diferenciam estas atividades, tais como as economias de escala, grau de dispersão geográfico, custos de saída, velocidade de retorno do investimento e importância dos fornecedores. Apesar desse alerta, alguns autores recorreram às teorias de negócios internacionais prevalentes - tanto as de abordagem econômica, quanto as de abordagem comportamental (cf. Carneiro \& Dib, 2007) - na tentativa de explicar o processo de IV, como no modelo proposto por Sternquist (1997) com base no Paradigma Eclético (Dunning, 1988) e no modelo proposto por Vida e Fairhurst (1998) que considera premissas do Modelo de Uppsala (Johanson \& Vahlne, 1977).

O debate envolveu ainda três importantes temas na construção da disciplina de IV: a) definição do escopo da atividade, b) identificação de elementos que caracterizariam uma firma como uma varejista internacional e c) agenda de pesquisa específica. A questão sobre o escopo da IV parte da ideia de que enquanto uma firma manufatureira exporta seus produtos/marcas para serem distribuídos em mercados exteriores, uma firma varejista "exporta" sua própria atividade de distribuição (Burt \& Mavrommatis, 2006). Segundo Dawson (1994), a IV se daria em termos de dimensões visíveis e invisíveis. As dimensões menos visíveis seriam as que se relacionam com a internacionalização dos investimentos financeiros exclusivamente e às compras internacionais. Na parte mais visível, estão a transferência de conhecimentos gerenciais e técnicos, por meio do estabelecimento de lojas nos mercados exteriores. Entretanto, para caracterização de uma firma varejista internacional, alguns autores preconizam que a presença de elementos da cadeia de valor da firma varejista que envolva mercados não-domésticos, como no caso de 
importação de outros países para distribuição no mercado doméstico, não é o que caracterizaria uma firma varejista internacional (Sternquist, 1997). Para tanto, uma varejista deve contar com a presença de lojas em mercados exteriores cuja operação esteja sob seu gerenciamento, excluindo com isso também casos nos quais a entrada no mercado exterior tenha se dado apenas por meio do fluxo de capital, sem controle da operação (Alexander \& Doherty, 2009).

O terceiro tema, que trata da importância em estabelecer uma agenda de investigação para o desenvolvimento do conhecimento e consolidação da pesquisa, propõe a divisão do conhecimento entre as etapas do processo de IV, tais como motivos para internacionalização, seleção de mercados de destino e padrões de operação. Swoboda et al. (2009) elencaram 105 artigos publicados em periódicos internacionais entre 1990 e 2008 e os agruparam em três temas: i) orientações básicas, que inclui estratégias e motivos de internacionalização; ii) orientações para o mercado, que inclui seleção e entrada nos mercados, operações e gerenciamento e iii) desempenho e insucesso. Os autores comentaram que o campo de IV ainda é jovem se comparado ao de negócios internacionais e sugerem avenidas de investigação em todos os temas, com destaque para estudos sobre desempenho e desinvestimento.

Mais recentemente, os pesquisadores vêm se deparado com dificuldades em explicar a IV de determinadas categorias nas quais a marca própria é determinante na estratégia de expansão, como moda e luxo. Isto decorre da presença maciça de pesquisas com varejistas de grandes formatos, como supermercados, que distribuem diversas marcas de terceiros (Gomes, 2016; Ilonen, Wren, Gabrielsson, \& Salimäki, 2011). Embora varejistas de grandes formatos ainda despertem a curiosidade de pesquisadores, sobretudo por sua relevância econômica no cenário internacional, as varejistas de moda e luxo têm mostrado intensa atividade internacional e vêm chamando a atenção de grupos de pesquisadores a ampliar o conhecimento específico na área (Arrigo, 2015; Doherty, 2009; Moore et al., 2010).

\section{Metodologia}

Revisões de literatura são uma ferramenta importante para a atividade acadêmica, reunindo informações sobre o que já se conhece e indicando novos caminho de pesquisa. Neste estudo, buscouse identificar a contribuição de pesquisas suportadas pelo método de EC na construção do conhecimento em IV por meio de uma revisão de artigos acadêmicos publicados em periódicos científicos de língua inglesa revisados por pares, entre os anos de 2000 e 2015. Visando superar algumas das falhas de revisões tradicionais com relação à sua replicação, optou-se pela adoção de um método de revisão sistemática de literatura, adaptada ao campo de gestão (Tranfield, Denyer, \& Smart, 2003), com protocolo de duas etapas, seguido do processo de classificação e análise. Na primeira etapa, fez-se uma busca nas bases de dados Ebsco, Web of Science, Scopus e ScienceDirect (termos de busca: "international* retail*" - para artigos sobre IV - e "case stud*" - para artigos que utilizaram método de EC), seguida de consulta à lista de referências dos artigos inicialmente encontrados. Após checagem de repetição, foi gerada uma lista de 193 artigos sobre IV. Na segunda etapa, foram selecionados apenas os artigos baseados em EC, resultando em uma base de 48 artigos.

A escolha de restringir esta pesquisa à artigos baseados em EC foi resultante da contribuição de EC na compreensão de fenômenos complexos no ambiente de negócios, pois possibilitam a observação do fenômeno no seu contexto natural e contemporâneo. Segundo Yin (2014, p. 14), "EC são uma estratégia de pesquisa que melhor responde a perguntas do tipo 'como' e 'por que' sobre eventos contemporâneos", sobre os quais o pesquisador tem pouco ou nenhum controle e para os quais a teoria é incipiente ou escassa, que parece ser o caso de IV. Dentre os 48 artigos baseados em EC analisados, foram encontrados tanto casos únicos quanto casos múltiplos. Casos únicos são considerados relevantes quando são críticos ou reveladores e permitem aprofundamento na pesquisa, enquanto que casos múltiplos facilitam a construção de teoria e permitem ao pesquisador extrapolar os resultados a outras situações similares (Ghauri, 2004).

Por último, os artigos foram então analisados e classificados de acordo com os principais temas de pesquisa sobre IV, segundo a organização proposta na revisão de literatura de IV elaborada por Swoboda et al. (2009): (i) motivações, (ii) estratégia, (iii) seleção e entrada nos mercados, (iv) padrões de operação nos mercados (incluindo aprendizado e adaptação) e (v) desempenho (incluindo desinvestimento). Além disso, para cada artigo foram identificados: a) 
número de casos, b) unidade de análise, c) ramo de atuação das firmas varejistas estudadas, e d) países/regiões de origem e de destino.

\section{Análise e discussão dos resultados}

Os artigos selecionados estão listados, agrupados por área temática em IV e descritos resumidamente na Tabela 1.

Tab 1

Lista dos EC em internacionalização varejista

\begin{tabular}{|c|c|c|c|}
\hline Tema em IV & Unidade de Análise & Resultados & Autores \\
\hline \multirow[t]{5}{*}{ Motivações } & (n=9), PMEs, Inglaterra & $\begin{array}{l}\text { Características da gestão - Identificação de fatores objetivos, } \\
\text { como contatos no exterior e experiência internacional, e } \\
\text { fatores subjetivos, como atitude perante o risco vindo dos } \\
\text { empreendedores. }\end{array}$ & $\begin{array}{l}\text { (Hutchinson, } \\
\text { Quinn, \& } \\
\text { Alexander, 2006) }\end{array}$ \\
\hline & $(n=9)$, PMEs, Inglaterra & $\begin{array}{l}\text { Apelo global da marca, experiência pessoal do } \\
\text { empreendedor e rede de relacionamentos são facilitadores } \\
\text { da motivação para internacionalizar }\end{array}$ & $\begin{array}{l}\text { (Hutchinson, } \\
\text { Alexander, Quinn, } \\
\text { \& Doherty, 2007) }\end{array}$ \\
\hline & $(n=6)$, PMEs, Inglaterra & $\begin{array}{l}\text { Barreiras internas e externas à internacionalização } \\
\text { relacionadas a (i) gerenciamento: falta de visão, medo de } \\
\text { perda de controle e falta de conhecimento; (ii) empresa: } \\
\text { transferência do conceito de varejo para ouros países, falta } \\
\text { de recursos e falta de consolidação no mercado doméstico; e } \\
\text { (iii) mercado externo: legislação, moeda, diferenças culturais } \\
\text { e logística. Percepção negativa de suporte governamental } \\
\text { para superar essas barreiras. }\end{array}$ & $\begin{array}{l}\text { (Hutchinson, } \\
\text { Fleck, \& Lloyd- } \\
\text { Reason, 2009) }\end{array}$ \\
\hline & $(n=8)$, PMEs, Inglaterra & $\begin{array}{l}\text { Barreiras internas e externas são inibidoras da expansão } \\
\text { internacional de PMEs. Aponta alguns meios de superar estas } \\
\text { barreiras, em especial destaque para apelo ao mercado de } \\
\text { luxo e marcas fortes. }\end{array}$ & $\begin{array}{l}\text { (Hutchinson, } \\
\text { Quinn, Alexander, } \\
\text { \& Doherty, 2009) }\end{array}$ \\
\hline & $(n=4)$, moda, Turquia & $\begin{array}{l}\text { Varejistas de países emergentes são entrantes tardios e se } \\
\text { internacionalizam por conta da ausência de oportunidades } \\
\text { no mercado doméstico }\end{array}$ & $\begin{array}{l}\text { (Eren-Erdogmus, } \\
\text { Cobanoglu, Yalcin, } \\
\text { \& Ghauri, 2010) }\end{array}$ \\
\hline \multirow[t]{4}{*}{ Estratégia } & $\begin{array}{l}(n=3), \text { supermercados, } \\
\text { Inglaterra }\end{array}$ & $\begin{array}{l}\text { Internacionalização provoca alterações na estratégia de } \\
\text { marca corporativa }\end{array}$ & $\begin{array}{l}\text { (Burt \& Sparks, } \\
\text { 2002) }\end{array}$ \\
\hline & $(n=5)$, moda, Inglaterra & $\begin{array}{l}\text { Identificação de capacidades dinâmicas na IV: de primeiro } \\
\text { nível, como aprendizado e orientação empreendedora, e } \\
\text { segundo nível, como construção de marca, gestão de lojas e } \\
\text { gestão de canal. }\end{array}$ & $\begin{array}{l}\text { (Frasquet, } \\
\text { Dawson, \& Mollá, } \\
\text { 2013) }\end{array}$ \\
\hline & $(n=9)$, PMEs, Inglaterra & $\begin{array}{l}\text { Além da forte imagem de marca, as empresas optam por } \\
\text { expandir doméstica e internacionalmente ao mesmo tempo } \\
\text { e são verticalmente integradas }\end{array}$ & $\begin{array}{l}\text { (Hutchinson \& } \\
\text { Quinn, 2011) }\end{array}$ \\
\hline & $(n=4)$, misto, Europa & $\begin{array}{l}\text { Modelo de estratégia de expansão de varejistas } \\
\text { manufatureiras baseado na ênfase em vendas (distribuição } \\
\text { terceirizada) versus ênfase em marca (distribuição própria) }\end{array}$ & $\begin{array}{l}\text { (Ilonen et al., } \\
\text { 2011) }\end{array}$ \\
\hline \multirow[t]{3}{*}{ Entrada } & $\begin{array}{l}(\mathrm{n}=6), \text { franquias, moda, } \\
\text { Inglaterra }\end{array}$ & $\begin{array}{l}\text { Fatores na opção por franquia: organizacionais (experiência } \\
\text { internacional, recursos, marca franqueada, influência dos } \\
\text { gestores) e ambientais (abordagem oportunista, } \\
\text { complexidade do mercado de destino, competição doméstica } \\
\text { e disponibilidade de parceiros para franquia). }\end{array}$ & (Doherty, 2007b) \\
\hline & $\begin{array}{l}(\mathrm{n}=6) \text {, franquias, } \\
\text { Inglaterra }\end{array}$ & $\begin{array}{l}\text { Seleção de franqueados internacionais: comportamentos } \\
\text { estratégicos (seleção de mercado antecede seleção de } \\
\text { parceiros) e oportunistas (seleção de parceiros antecede } \\
\text { seleção de mercado). }\end{array}$ & (Doherty, 2009) \\
\hline & $(n=3)$, misto, Inglaterra & $\begin{array}{l}\text { Para mitigar riscos e acelerar aprendizado, a firma estabelece } \\
\text { redes de parcerias nos mercados locais e mantém } \\
\text { coordenação centralizada. }\end{array}$ & $\begin{array}{l}\text { (Girod \& Rugman, } \\
\text { 2005) }\end{array}$ \\
\hline
\end{tabular}




\begin{tabular}{|c|c|c|}
\hline$(n=4)$, misto, Inglaterra & $\begin{array}{l}\text { Distância cultural, falta de informação, importância da rede } \\
\text { local e reputação do país de origem levam à resistência da } \\
\text { firma a um mercado e à opção por joint ventures. }\end{array}$ & $\begin{array}{l}\text { (Palmer, Owens, } \\
\text { \& De Kervenoael, } \\
\text { 2010) }\end{array}$ \\
\hline$(n=6)$, moda, França & $\begin{array}{l}\text { Indicação de vários modos de entrada utilizados por } \\
\text { varejistas de moda na internacionalização, desde a abertura } \\
\text { de lojas próprias, passando pela venda através de canais } \\
\text { multimarcas, até o uso de shop-in-shop. }\end{array}$ & $\begin{array}{l}\text { (Picot-Coupey, } \\
2006 \text { ) }\end{array}$ \\
\hline $\begin{array}{l}(\mathrm{n}=13) \text {, varejistas de } \\
\text { marcas próprias de } \\
\text { várias categorias }\end{array}$ & $\begin{array}{l}\text { A implantação de lojas temporárias permite testar e adaptar } \\
\text { a operação ao consumidor do mercado de destino, } \\
\text { desenvolver e sustentar a marca própria e desenvolver redes } \\
\text { de relacionamentos com vários stakeholders. }\end{array}$ & $\begin{array}{l}\text { (Picot-Coupey, } \\
\text { 2014) }\end{array}$ \\
\hline
\end{tabular}

Ikea, móveis, Suécia Entrada na Rússia/China: reconhecimento de que existem diferentes atores da rede de relacionamentos e

(Elg et al., 2008) gerenciamento diferenciado em cada fase da entrada no mercado

$(n=6)$, varejistas de A presença de várias lojas-conceito de marcas de luxo luxo aglomeradas em espaços urbanos dota o espaço de um "senso de luxo". Portanto, localização de flagship stores de marcas concorrentes é uma atividade de co-branding.

$(n=20)$, varejistas de Varejistas de luxo optaram por estabelecer acordos com luxo distribuidores exclusivos e implantar lojas próprias, escolheram locais emblemáticos, como hotéis e shopping centers, e investiram no crescimento contínuo para aumentar presença no mercado.

$\begin{array}{ll}\text { Operação } & \begin{array}{l}\text { Dia, supermercado, } \\ \text { Espanha }\end{array}\end{array}$
Comparação da percepção imagem de loja entre consumidores do país de origem e de destino (Grécia): embora a percepção seja diferente entre os países, a loja é percebida de forma semelhante em relação aos concorrentes locais.

(n=13), varejistas de Identifica três tipos: a) "glocal": alta internacionalização e moda alta participação do varejo direto, b) híbrido: internacionalização não é diretamente relacionada com o varejo direto e c) orientado para estilo: baixa internacionalização e baixa participação do varejo direto.

$(n=6)$, franquias, moda, Associação do relacionamento entre franqueador e Inglaterra franqueado com o processo de "casamento", envolvendo o reconhecimento da necessidade de um parceiro, a avaliação e a atração.

(Arrigo, 2015)

(Bonetti, 2014)

(Burt \&

Mavrommatis, 2006)

\section{(Caniato, Caridi,} Moretto, Sianesi, \& Spina, 2014)

(Doherty \&

Alexander, 2004)

$(n=6)$, franquias, moda, Contratos não são a única forma de controle das franquias Inglaterra em IV. A varejista pode exercer controle por meio da seleção e relacionamento com franqueados em base de confiança e estabelecimento de máster-franqueados

( $n=6)$, franquias, moda, Mecanismos de suporte à rede franqueada: modelo Inglaterra conceitual oferece dois níveis de suporte: gestão estratégica (planejamento, análise de mercado, monitoramento financeiro) e suporte operacional (abertura de lojas, treinamento e marketing).

Home Depot, Entrada no Canadá afetou competidores e consumidores bricolagem, EUA adotaram o novo estilo de varejo

(Hernandez, 2003)

(Doherty \&

Alexander, 2006)

(Doherty, 2007a)

Debenhams, loja

Descreve os detalhes da entrada e operação em mercados

(Jones, 2003)

depto., Inglaterra culturalmente distantes (Oriente Médio) e o papel do parceiro local 


\begin{tabular}{|c|c|c|}
\hline Ikea, móveis, Suécia & $\begin{array}{l}\text { Importância do aprendizado (entrada na Rússia): } \\
\text { conhecimento sobre o mercado varia em função da fase da } \\
\text { entrada e operação. Modelos do processo de aprendizado } \\
\text { devem ser expandidos. }\end{array}$ & $\begin{array}{l}\text { (Jonsson \& Elg, } \\
\text { 2006) }\end{array}$ \\
\hline Ikea, móveis, Suécia & $\begin{array}{l}\text { Aprendizado "para frente", reverso e lateral entre matriz e } \\
\text { subsidiárias aceleram processo de aprendizado (operações } \\
\text { da China, Japão e Rússia) }\end{array}$ & (Jonsson, 2008) \\
\hline $\begin{array}{l}(n=10), \text { moda, Europa/ } \\
\text { EUA }\end{array}$ & $\begin{array}{l}\text { Resolução de conflitos na cadeia: ferramentas coercitivas de } \\
\text { controle não se aplicam ao varejo de moda, pois a } \\
\text { participação da equipe de lojas é fundamental no } \\
\text { desenvolvimento da marca. }\end{array}$ & $\begin{array}{l}\text { (Moore, } \\
\text { Birtwistle, \& Burt, } \\
\text { 2004) }\end{array}$ \\
\hline $\begin{array}{l}\text { Tesco, hipermercado, } \\
\text { Inglaterra }\end{array}$ & $\begin{array}{l}\text { Aprendizado é facilitado por incertezas e choques no } \\
\text { mercado internacional, inibido pelo tamanho do mercado } \\
\text { doméstico e não necessariamente se dá em estágios }\end{array}$ & (Palmer, 2005) \\
\hline $\begin{array}{l}\text { Wal-Mart, } \\
\text { hipermercado, EUA }\end{array}$ & $\begin{array}{l}\text { Aprendizados relativos à reação da concorrência instalada ao } \\
\text { novo entrante em mercado emergente (Brasil) }\end{array}$ & $\begin{array}{l}\text { (Rocha \& Dib, } \\
\text { 2002) }\end{array}$ \\
\hline $\begin{array}{l}\text { Tesco, hipermercado, } \\
\text { Inglaterra }\end{array}$ & $\begin{array}{l}\text { Apesar de diferenças culturais, a orientação para mercado na } \\
\text { adaptação do marketing mix a países emergentes (Leste } \\
\text { Europeu) possui correlação com o desempenho }\end{array}$ & $\begin{array}{l}\text { (Rogers, Ghauri, } \\
\text { \& George, 2005) }\end{array}$ \\
\hline Tessilform, moda, Itália & $\begin{array}{l}\text { Reorganização da rede de relacionamentos para melhor } \\
\text { suportar as operações internacionais (China) }\end{array}$ & $\begin{array}{l}\text { (Guercini \& } \\
\text { Runfola, 2010) }\end{array}$ \\
\hline Zara, moda, Espanha & $\begin{array}{l}\text { Sucesso na IV decorre do compartilhamento do } \\
\text { conhecimento na cadeia internacional, incluindo loja, e } \\
\text { vantagens de integração vertical. Expansão inicial seguiu } \\
\text { distância psíquica, mas com aprendizado adquirido esta } \\
\text { barreira foi rapidamente superada }\end{array}$ & $\begin{array}{l}\text { (Bhardwaj, } \\
\text { Eickman, \& } \\
\text { Runyan, 2011) }\end{array}$ \\
\hline $\begin{array}{l}\text { Fallabela, loja depto., } \\
\text { Chile }\end{array}$ & $\begin{array}{l}\text { Recursos e competências da varejista chilena no } \\
\text { estabelecimento de parcerias, inovação e capacidade de } \\
\text { aprendizado e adaptação: fundamentais para uma expansão } \\
\text { de sucesso na América Latina }\end{array}$ & (Bianchi, 2009) \\
\hline $\begin{array}{l}\text { Fallabela, loja depto., } \\
\text { Chile }\end{array}$ & $\begin{array}{l}\text { IV na América Latina de varejista chilena foi legitimada pelo } \\
\text { cumprimento das normas sociais nos mercados, com base no } \\
\text { ingresso em redes de relacionamento, aprendizado } \\
\text { organizacional e equipe experiente. }\end{array}$ & (Bianchi, 2011) \\
\hline $\begin{array}{l}\text { Carrefour, } \\
\text { hipermercado, França }\end{array}$ & $\begin{array}{l}\text { Razões do sucesso na operação do Brasil: competências e } \\
\text { cultura organizacionais oferecem vantagens com relação ao } \\
\text { formato de lojas, localização e relacionamento } \\
\text { c/consumidor. }\end{array}$ & (Diallo, 2012) \\
\hline Zara, moda, Espanha & $\begin{array}{l}\text { Fatores determinantes do sucesso na IV: internacionalização } \\
\text { inicialmente em estágios, impulsionada pela restrição de } \\
\text { crescimento no mercado doméstico e pelas oportunidades } \\
\text { internacionais. Verticalmente integrada e focar na imagem } \\
\text { das lojas }\end{array}$ & $\begin{array}{l}\text { (Lopez \& Fan, } \\
\text { 2009) }\end{array}$ \\
\hline $\begin{array}{l}(\mathrm{n}=2), \text { moda, } \\
\text { Inglaterra/EUA }\end{array}$ & $\begin{array}{l}\text { Força da marca, gestão de exclusividade na distribuição, } \\
\text { controle cuidadoso da operação varejista alinhado à imagem } \\
\text { da marca são determinantes do desempenho na IV. }\end{array}$ & $\begin{array}{l}\text { (Wigley \& Moore, } \\
\text { 2007) }\end{array}$ \\
\hline $\begin{array}{l}(\mathrm{n}=2), \text { moda, } \\
\text { Inglaterra/EUA }\end{array}$ & $\begin{array}{l}\text { Percorre várias etapas do processo de internacionalização e } \\
\text { contribui com tipologia de "oportunista proativo" e } \\
\text { "oportunista reativo". Identifica que a força da marca e a } \\
\text { qualidade distintiva dos produtos são os principais elementos } \\
\text { de sucesso na IV }\end{array}$ & $\begin{array}{l}\text { (Wigley, Moore, } \\
\text { \& Birtwistle, } \\
\text { 2005) }\end{array}$ \\
\hline
\end{tabular}




\begin{tabular}{|c|c|c|c|}
\hline & $\begin{array}{l}\text { Per Una, moda, } \\
\text { Inglaterra }\end{array}$ & $\begin{array}{l}\text { Sucesso decorre do monitoramento das percepções dos } \\
\text { consumidores no mercado de destino (marca, preço e } \\
\text { produto), mantendo uma política global consistente. } \\
\text { Demanda iniciativas estratégias da matriz, porém adaptações } \\
\text { táticas dos franqueados no destino }\end{array}$ & $\begin{array}{l}\text { (Wigley \& Chiang, } \\
\text { 2009) }\end{array}$ \\
\hline \multirow[t]{8}{*}{ Desinvestimento } & $(n=2)$, moda, Inglaterra & $\begin{array}{l}\text { Identifica fases do processo de desinvestimento e aponta } \\
\text { franquia como alternativa de permanência no mercado }\end{array}$ & $\begin{array}{l}\text { (Alexander \& } \\
\text { Quinn, 2002) }\end{array}$ \\
\hline & $\begin{array}{l}\text { Home Depot, } \\
\text { bricolagem, EUA }\end{array}$ & $\begin{array}{l}\text { Desinvestimento de firma internacional no Chile como } \\
\text { resultado da inadequação às normas institucionais do } \\
\text { mercado de destino }\end{array}$ & $\begin{array}{l}\text { (Bianchi \& Arnold, } \\
\text { 2004) }\end{array}$ \\
\hline & $\begin{array}{l}(\mathrm{n}=4), \\
\text { supermercados/loja } \\
\text { depto, Europa/EUA }\end{array}$ & $\begin{array}{l}\text { Desinvestimento de varejistas internacionais no Chile: firmas } \\
\text { estrangeiras devem cumprir normas institucionais dos } \\
\text { mercados de destino e adquirir legitimidade na sociedade } \\
\text { para obterem sucesso }\end{array}$ & $\begin{array}{l}\text { (Bianchi \& Ostale, } \\
\text { 2006) }\end{array}$ \\
\hline & $\begin{array}{l}\text { Marks\&Spencer, loja } \\
\text { depto., Inglaterra }\end{array}$ & $\begin{array}{l}\text { Razões do desinvestimento em vários mercados: falta de uma } \\
\text { estratégia geral para a internacionalização, diferenciais da } \\
\text { firma no país de origem não foram percebidos no destino, } \\
\text { ausência de sistemas de controle adequados. }\end{array}$ & $\begin{array}{l}\text { (Burt, Mellahi, } \\
\text { Jackson, \& Sparks, } \\
\text { 2002) }\end{array}$ \\
\hline & $\begin{array}{l}(\mathrm{n}=1) \text {, varejista de } \\
\text { moda não identificado, } \\
\text { Inglaterra }\end{array}$ & $\begin{array}{l}\text { Desinvestimento é impactado pela cultura corporativa, } \\
\text { estabilidade no mercado doméstico, percepção geral do } \\
\text { desempenho da internacionalização, nova gestão e modo de } \\
\text { entrada. Mudanças na gestão são uma importante condição } \\
\text { para o desinvestimento }\end{array}$ & $\begin{array}{l}\text { (Cairns, Marie } \\
\text { Doherty, } \\
\text { Alexander, \& } \\
\text { Quinn, 2008) }\end{array}$ \\
\hline & $(n=7)$, misto, Inglaterra & $\begin{array}{l}\text { Desinvestimento como resultado de crise corporativa, } \\
\text { reestruturação interna ou mudança de foco, ou como } \\
\text { resultado de uma reestruturação positiva da firma, como a } \\
\text { reorientação da estratégia internacional versus doméstica }\end{array}$ & $\begin{array}{l}\text { (Cairns, Quinn, } \\
\text { Alexander, \& } \\
\text { Doherty, 2010) }\end{array}$ \\
\hline & $\begin{array}{l}\text { Ahold, hipermercado, } \\
\text { Holanda }\end{array}$ & $\begin{array}{l}\text { Desinvestimento é um construto multidimensional e envolve } \\
\text { reações às mudanças em mercados de destino e/ou é } \\
\text { resultado de decisões estratégicas da firma. Além disso, as } \\
\text { decisões variam em diferentes mercados }\end{array}$ & $\begin{array}{l}\text { (Palmer \& Quinn, } \\
\text { 2007) }\end{array}$ \\
\hline & $\begin{array}{l}\text { Marks\&Spencer, loja } \\
\text { depto, Inglaterra }\end{array}$ & $\begin{array}{l}\text { Decisões estratégicas e crises internas, aliadas à crise no } \\
\text { mercado de destino, promoveram insucesso em Hong Kong. } \\
\text { A firma aprendeu que adaptação e conhecimento ocorrem } \\
\text { em reciprocidade entre a firma e a subsidiária. } \\
\text { Desinvestimento se deu com troca do modo de operação } \\
\text { (franquia). }\end{array}$ & $\begin{array}{l}\text { (Jackson \& } \\
\text { Sparks, 2005) }\end{array}$ \\
\hline
\end{tabular}

Fonte: elaboração própria

\subsection{Descrição da amostra}

Na Tabela 2, nota-se a prevalência de estudos sobre varejistas originárias de mercados desenvolvidos, representando 45 dos 48 artigos analisados, com destaque para o Reino Unido, com 24 artigos, seguido de outros países europeus. É interessante notar a baixa participação de estudos sobre firmas oriundas dos EUA e a franca liderança de estudos com firmas europeias, conforme já apontado por Alexander e Doherty (2010). Apenas três artigos traziam estudos sobre a internacionalização de varejistas originárias de países emergentes. Com relação aos mercados de destino, em 29 dos 48 artigos não são especificados os mercados de destino, porém nota-se uma maior participação dos mercados emergentes, estudados em 12 artigos. 
Tab. 2

Países e regiões envolvidos nos artigos selecionados

\begin{tabular}{lcc}
\hline & \multicolumn{2}{c}{ Mercados } \\
Países / Regiões & Origem & Destino \\
\hline Desenvolvidos & 45 & 7 \\
\hline Inglaterra & 24 & 1 \\
Europa-outros & 15 & 4 \\
EUA & 3 & 0 \\
Vários & 3 & 2 \\
\hline Emergentes & 3 & 12 \\
\hline Chile & 2 & 2 \\
Turquia & 1 & 2 \\
América Latina & 0 & 2 \\
Oriente Médio & 0 & 1 \\
Leste Europeu & 0 & 1 \\
Ásia & 0 & 4 \\
\hline Vários (sem especificação) & 0 & 29 \\
\hline Total & 48 & 48 \\
\hline
\end{tabular}

Fonte: elaboração própria

Os artigos selecionados na amostra foram publicados em 29 diferentes periódicos; porém é clara a liderança dos periódicos International Journal of Retail and Distribution Management e The International Review of Retail, Distribution and Consumer Research, nos quais foram publicados 11 artigos em cada um desses periódicos, dentre os 48 artigos selecionados.

Na Tabela 3, nota-se um certo equilíbrio na amostra entre estudos de casos únicos e de casos múltiplos, com 21 e 27 artigos, respectivamente, dentre os 48 selecionados. Com relação ao tipo de firma varejista estudada, 18 artigos estudaram varejistas de que operam com lojas de grandes formatos, como hipermercados e lojas de departamento e 15 artigos estudaram varejistas de moda (incluindo luxo). Franquias varejistas e pequenas e médias empresas (PME) foram objeto de cinco estudos cada.

Tab. 3

Tipo de varejista estudado nos artigos selecionados

Estudos de Caso

\begin{tabular}{cccc} 
Tipo Varejista & Múltiplo & Único & Total \\
\hline Grande porte & 2 & 16 & 18 \\
Moda & 10 & 5 & 15 \\
Franquias & 5 & 0 & 5 \\
PME & 5 & 0 & 5 \\
Vários & 5 & 0 & 5 \\
\hline Total & 27 & 21 & 48
\end{tabular}

Fonte: elaboração própria
Com relação aos temas estudados, a amostra foi classificada segundo modelo utilizado por Swoboda et al. (2009), no qual os artigos em IV são classificados em seis categorias temáticas - a saber: motivações, estratégias, modos de entrada, operações, desempenho e desinvestimento - buscando-se com isso a construção de um padrão de análise comparativo.

Na Tabela 3 são apresentadas, por tema de IV, a distribuição da amostra do estudo de Swoboda et al. (2009) - que inclui pesquisas quantitativas e qualitativas, com predomínio da primeira - e a distribuição da amostra desta pesquisa. No estudo de Swoboda et al. (2009), nota-se um equilíbrio entre temas de IV pesquisados, com destaque apenas para aqueles que envolveram modos de entrada na IV, com 33\% da amostra. Já na amostra desta pesquisa, nota-se a prevalência de estudos de caso sobre atividades de IV que ocorrem no âmbito dos mercados de destino, representadas por estudos sobre o padrão de operação adotado nesses mercados, com 33\% da amostra, e de estudos sobre desempenho e desinvestimento, com $17 \%$ da amostra para cada tema. A maior relevância das áreas temáticas identificadas na amostra deste estudo reflete os apelos de autores na área de IV em busca de aprofundamento no conhecimento sobre essas etapas do processo e na construção de novas teorias (Alexander e Doherty, 2010; Picot-Coupey et al., 2014; Swoboda et al., 2009).

Tab. 4:

RI Temas de IV abordados nos artigos selecionados

\begin{tabular}{llccc}
\hline Temas in IV & $\begin{array}{l}\text { Amostra do estudo de } \\
\text { Swoboda et al. (2009) }\end{array}$ & \multicolumn{2}{c}{$\begin{array}{c}\text { Amostra de estudo de } \\
\text { caso em IV }\end{array}$} \\
\hline Motivações & 14 & $13 \%$ & 5 & $10 \%$ \\
Estratégia & 13 & $13 \%$ & 4 & $8 \%$ \\
Entrada & 34 & $33 \%$ & 7 & $15 \%$ \\
Operações & 17 & $16 \%$ & 16 & $33 \%$ \\
Desempenho & 13 & $13 \%$ & 8 & $17 \%$ \\
\hline Desinvestimento & 13 & $13 \%$ & 8 & $17 \%$ \\
\hline Total & 104 & $100 \%$ & 48 & $100 \%$
\end{tabular}

Fonte: elaboração própria

\subsection{Análises por temas de IV}

\subsubsection{Motivações}

As pesquisas sobre motivações para IV foram concentradas em firmas que enfrentam barreiras na internacionalização, quais sejam, pequenas e médias empresas (PME) e firmas oriundas de países emergentes. 
Hutchinson e colegas lideraram um grupo de pesquisas sobre internacionalização de PMEs varejistas. Dentre os achados, foi identificado que para essas empresas as motivações para internacionalização são influenciadas por fatores subjetivos - como a experiência pessoal dos empreendedores e sua postura diante do risco (Hutchinson et al., 2006), e fatores objetivos - como o papel das redes de relacionamento no exterior (Hutchinson et al., 2007) e experiência internacional dos empreendedores (Hutchinson et al., 2006). Além disso, para PMEs que têm marcas próprias, a imagem internacional da marca é a principal motivação da sua internacionalização e pode ser uma forma de superar barreiras à internacionalização (Hutchinson, Quinn et al., 2009).

Em estudo sobre varejistas de país emergente, Eren-Erdogmus e colegas (2010) observaram que a principal motivação da internacionalização de varejistas de moda turcas, entrantes tardias nos mercados internacionais, foi a falta de oportunidades domésticas de crescimento.

\subsubsection{Estratégia}

Nos estudos sobre estratégia, foram destacados os elementos capazes de afetar a internacionalização das firmas oriundos de especificidades do tipo de firma varejista. $\mathrm{Na}$ IV de moda, os achados convergiram para dois elementos importantes na expansão internacional: construção de marca e gestão de rede de lojas (Frasquet et al., 2013; Hutchinson et al., 2007). Para varejistas fabricantes, foi identificado um padrão no estabelecimento da sua distribuição internacional. Enquanto que a distribuição por terceiros tem como objetivo aumentar cobertura de vendas, a distribuição pelo meio de lojas monomarca tem como foco a disseminação da marca própria e a entrega de uma experiência completa ao consumidor (Ilonen et al., 2011).

Para varejistas multimarcas, como supermercados, as marcas não são associadas aos produtos e sim à própria corporação. Burt e Sparks (2002) destacaram que a internacionalização é capaz de alterar a estratégia de marca corporativa, considerando que a percepção nos mercados exteriores pode não ser semelhante àquela no mercado doméstico. Com isso, uma estratégia de marca corporativa varejista com valores que tenham apelo em vários mercados passa a compor um prérequisito para sua atuação internacional.

\subsubsection{Entrada em novos mercados}

No tema relativo à entrada em mercados internacionais, foram abordadas as questões relativas à percepção de risco e à decisão de comprometimento de custo e de controle, tendo em vista a escala de risco/custo/controle de modos de entrada na IV, na qual no topo superior da escala estão as expansões orgânicas e, no outro extremo, estão as franquias, enquanto que os joint ventures estão em um nível imediatamente abaixo à expansão orgânica.

Franquias foram objeto de estudo aprofundado de Doherty, com base em varejistas de moda do Reino Unido. Segundo Doherty (2007a), a opção por franquia como modo de entrada requer algumas précondições, e não se trata apenas de uma decisão de risco e custo. Essa opção é decorrente de uma combinação de fatores organizacionais - como experiência internacional dos gestores e marca passível de ser franqueada, e ambientais - como a complexidade do mercado de destino e a disponibilidade de parceiros para franquia no mercado de destino. A autora destacou que uma firma adota um comportamento estratégico quando decide entrar em um mercado após ter escolhido os parceiros locais. Do contrário, seu comportamento é oportunista e sujeito a riscos maiores (Doherty, 2009).

No estudo de Picot-Coupey (2006), a autora destacou que varejistas de moda têm alternativas de entrada mais flexíveis do que varejistas tradicionais e a opção de modo de entrada depende das características do país de destino e da velocidade desejada para expansão. Além disso, diferentemente de outros tipos de varejistas tradicionais, as varejistas de moda e de outros setores com marca própria, como móveis, podem optar por modos de entrada anteriores ao estabelecimento da cadeia de lojas, como vendas por atacado no país de destino, mostrando semelhanças com firmas manufatureiras (Ilonen et al., 2011). Podem também, como as demais firmas, estabelecer cadeias de lojas próprias ou franqueadas, operadas por elas mesmas ou por parceiros regionais. Isso implica em uma sofisticada gestão de canal, capacidade pouco considerada na literatura de IV, e também característica de firmas manufatureiras. 
As redes no mercado de destino aparecem como elementos influenciadores na entrada em novos mercados. No estudo de Girod e Rugman (2005), o estabelecimento de parcerias nos mercados de destino é capaz de mitigar riscos e acelerar o aprendizado. Em estudo específico sobre a Ikea, Elg et al. (2008) identificaram a existência de diferentes atores nas redes de relacionamento no mercado de destino, com graus de importância variados de acordo com a etapa do processo de entrada. Segundo os autores, identificar estes atores e gerenciá-los de forma diferenciada foi capaz de promover uma entrada suave da Ikea na Rússia e na China, mercados complexos e distantes culturalmente da firma sueca.

Palmer e Owens (2006) contribuíram no conhecimento sobre modo de entrada na IV ao revelarem que a opção por joint ventures, embora comumente justificada pela vantagem do compartilhamento de recursos, pode também ser adotada para mitigar distância cultural e ganhar tempo no aprendizado, contribuindo com uma visão mais voltada à exploração do que ao compartilhamento dos recursos.

\subsubsection{Operações}

Os estudos sobre padrões de operações respondem a questões relativas ao mix de marketing adotado pelas firmas no mercado de destino e ao aprendizado decorrente da experiência internacional, tanto aqueles específicos de um determinado mercado e a concorrência instalada, quanto aqueles que afetam o processo de internacionalização da firma (Swoboda et al., 2009). A adaptação do marketing mix ao mercado de destino é considerada elemento fundamental na operação varejista de supermercados nos estudos selecionados (Burt e Mavrommatis, 2006; Rogers et al., 2005). No entanto, o debate se estende quando se trata de varejistas de moda ou de luxo, cuja padronização é considerada como principal vantagem competitiva da firma em mercados internacionais (llonen et al., 2011; Moore et al, 2000; Wigley \& Chiang, 2009).

Com relação ao controle das operações nos mercados de destino, Doherty e Alexander (2006) desenvolveram um corpo teórico sobre franquias internacionais com base no relacionamento entre franqueadores e franqueados. Os autores reforçam que métodos coercitivos (contratos) são pouco eficazes em mercados tão espalhados e distantes e que métodos não-coercitivos, baseados em suporte e monitoramento, devem prevalecer. Para tanto, as firmas devem ter estrutura organizacional suficiente e qualificada para gerenciar uma rede internacional, com critérios rígidos de seleção de novos franqueados, em analogia a um casamento (Doherty \& Alexander, 2004).

O aprendizado oriundo da expansão internacional da Ikea foi palco de estudos sobre aprendizado, nos quais Jonsson e Elg (2006) observaram que o conhecimento sobre o mercado de destino varia em função da fase da entrada e operação e por isso os modelos do processo de aprendizado devem ser expandidos para melhor explicar o desempenho das firmas na IV. Em outro estudo sobre a Ikea, Jonsson (2008) destacou que os aprendizados "para frente" (da matriz para subsidiária), reverso (da subsidiária para matriz) e lateral (entre subsidiárias) foram capazes de acelerar o processo de aprendizado da empresa na IV. As redes de relacionamento também aparecem como fundamentais no processo de aprendizado, como no estudo sobre implantação de varejista de moda italiana na China (Guercini \& Runfola, 2010), no qual a varejista se viu obrigada a reorganizar suas redes de relacionamento, inclusive aquelas no seu país de origem, para operar adequadamente neste mercado.

Com relação ao impacto da operação da varejista internacional no mercado de destino, dois EC selecionados apresentam resultados opostos. Enquanto que Rocha e Dib (2002) relataram que a entrada do Wal-Mart no Brasil contribuiu para mudanças no padrão de operação das varejistas domésticas e a firma entrante foi alvo de retaliações, Hernandez (2003) retratou que o Home Depot instalou seu formato inovador no Canadá, com boa aceitação do consumidor e acomodação natural dos concorrentes instalados.

\subsubsection{Desempenho}

O desempenho das varejistas é analisado em EC sob a ótica do sucesso e do desinvestimento, que pode ocorrer por insucesso ou decisão estratégica

$\mathrm{Na}$ análise do sucesso de varejistas de moda, os elementos salientes referem-se à força da marca e à cadeia de valor estabelecida, incluindo das decisões de canais de distribuição (Wigley et al., 2005; Wigley \& Moore, 2007), elementos pouco estudados na literatura de IV por serem normalmente associadas a firmas manufatureiras. No entanto, o segmento de 
moda caracteriza-se por um alto grau de verticalização e por isso outros elementos da cadeia de valor devem ser incorporados nos modelos de internacionalização de suas operações varejistas, como demonstrado no caso da Zara (Lopez \& Fan, 2009). Wigley e Chiang (2009), em EC sobre varejista de moda italiana, concluíram que o sucesso internacional da firma foi decorrente do monitoramento das percepções dos consumidores no mercado de destino sobre marca, preço e produto, mantendo uma política global consistente. Os autores contribuíram no debate sobre padronização vs adaptação ao indicarem que franquias no mercado de destino podem adotar ações táticas, desde que aprovadas pela matriz. Em contraponto, no caso sobre a operação do Carrefour no Brasil, Diallo (2012) indicou que seu sucesso foi resultado da adaptação do marketing mix e da orientação internacional da equipe à cultura local.

O sucesso na expansão internacional de varejistas de países emergentes, foi descrito por Bianchi em dois EC longitudinais que revelaram os recursos e capacidades usados pela firma de país emergente, a chilena Fallabela, para competir com varejistas originários de países desenvolvidos instalados no mercado de destino. No primeiro estudo (Bianchi, 2009), as razões de sucesso da empresa identificadas estão consideradas nos modelos teóricos existentes relativamente às vantagens de propriedade, aprendizado organizacional e expansão para países fronteiriços (Sternquist, 1997). No estudo subsequente, Bianchi (2011) acrescentou que, por conhecer profundamente e respeitar as normas sociais dos países de destino, a varejista teria conseguido, com sucesso, nivelar-se a seus concorrentes norte-americanos e europeus lá instalados, mesmo não desfrutando das mesmas vantagens de origem. Com isso, a autora pretendeu demonstrar que os postulados da teoria institucional devem ser considerados nos modelos de IV, sobretudo em países emergentes. A ausência de conformidade às normas institucionais do mercado de destino parece ter sido razão preponderante para explicar o insucesso, e consequente desinvestimento, de grandes varejistas interacionais oriundos de países desenvolvidos no Chile, como no caso do Home Depot e outros (Bianchi \& Ostale, 2006).

Bianchi ainda contribuiu no conhecimento sobre a IV de firmas oriundas de mercados emergentes ao destacar dois fatores para o sucesso da chilena Fallabela em expansão na América Latina. O primeiro deles refere-se aos recursos e competências organizacionais, como orientação para inovação e capacidade de aprendizado e adaptação, na tradição da Visão Baseada em Recursos. O segundo atribui o sucesso à legitimidade social obtida nos mercados de destino.

Por fim, confrontos com teorias de negócios internacionais contribuíram para ressaltar as especificidades da IV. No estudo sobre a rede supermercadista inglesa Tesco, Palmer (2005) identificou que sua expansão internacional não se deu de forma incremental, como preconizado pelo Modelo de Uppsala (Johanson \& Vahlne, 1977), mas - em muitas ocasiões - a empresa oportunisticamente optou por expandir-se para mercados onde havia disponibilidade de espaços e consumidores não atendidos, em linha com as vantagens de localização defendidas no Paradigma Eclético (Dunning, 1988). O caso ainda aponta que o aprendizado resultante da internacionalização não foi incorporado pela empresa para corrigir ações futuras. Já no estudo sobre o sucesso da espanhola de moda Zara (Lopez e Fan, 2009), a expansão da varejista pareceu seguir o Modelo de Uppsala (Johanson \& Vahlne, 1977), já que a empresa teria ingressado inicialmente em mercados psiquicamente próximos para posterior expansão para países mais distantes. Porém, sua rápida e extensa expansão internacional, turbinada por uma cadeia produtiva eficaz e imagem da marca, encontra explicação também nas vantagens de propriedade, segundo o Paradigma Eclético de Dunning (1988).

\subsubsection{Desinvestimento}

O desinvestimento é tema ainda pouco estudado na literatura de IV, segundo alguns autores, por conta de sua natureza multifacetada e complexa e, ainda, à dificuldade em obter-se informações primárias (Alexander \& Doherty, 2010). No entanto, vem recebendo contribuições importantes dos EC, que são o método predominante nesta área temática em IV. Apesar da ausência de modelos robustos, alguns achados ganharam consistência entre os EC como antecedentes do desinvestimento.

Desinvestimentos podem acontecer como reação a mudanças nos mercados de destino, mudanças no mercado doméstico ou como resultados de mudanças estratégicas e organizacionais nas firmas (Cairns et al., 2008; Palmer \& Quinn, 2007). Falhas em estabelecer uma estrutura organizacional 
apropriada para operar internacionalmente foram identificadas como elemento precursor do desinvestimento maciço da Marks\&Spencer em vários mercados durante a década de 1990 (Burt et al., 2002). Entretanto, o desinvestimento não significou necessariamente abandono do mercado de destino e a mudança de modo de operação, como estabelecimento de franquias em substituição a lojas próprias, representou uma alternativa de permanência no mercado (Alexander \& Quinn, 2002).

\section{Conclusões}

A aplicação de EC na investigação dos fenômenos ligados à IV, apesar de contar com as limitações inerentes ao método, tem contribuído com elementos teóricos relevantes na compreensão do processo. Especialmente em negócios internacionais, a influência do contexto no fenômeno, haja vista a diversidade de países e culturas, bem como as situações históricas envolvendo os processos de internacionalização, indica O EC como um método fundamental para o entendimento da complexidade que envolve o processo de IV (Piekkari, Welch, \& Paavilainen, 2009).

Com base na presente pesquisa, conclui-se que a aplicação de EC em IV vem contribuindo tanto para o conhecimento de fenômenos específicos de varejistas e suas idiossincrasias, quanto na construção de nova teoria aplicável a diferentes formatos varejistas - como as franquias e PMEs - cujo processo de internacionalização se dá em bases diferentes daquele observado para varejistas tradicionalmente pesquisadas, como supermercados.

Entretanto, há ainda muitos caminhos para novas investigações e aprofundamento dos achados oriundos dos EC em IV sobretudo no que tange a: a) desinvestimento varejista internacional, b) segmentos varejistas que operam exclusivamente com marca própria, como moda e artigos de luxo, c) varejistas provenientes de países emergentes, d) papel das redes de relacionamento na IV. Com relação a esse último item, foi interessante notar que o uso das redes de relacionamento na IV pode facilitar a entrada e a sequência de expansão nos mercados de destinos e acelerar o aprendizado sobre os mercados de destino, sobretudo naqueles com grande distância cultural dos mercados desenvolvidos, como observados nos vários estudos sobre Ikea aqui analisados.
Esta revisão sistemática de literatura contribui, portanto, para o conhecimento acadêmico e gerencial, ao oferecer um ponto de partida para acadêmicos interessados em IV e evidenciar algumas lacunas no conhecimento acadêmico, ao mesmo tempo disponibilizando estudos de casos reais, com seus aprendizados e conclusões de forma sumarizada para o corpo gerencial das empresas.

\section{Referências}

- Alexander, N. (1990). Retailers and International Markets: Motives for Expansion. International Marketing Review, 7(4), 75-85.

- Alexander, N., \& Doherty, A. M. (2010). International retail research: focus, methodology and conceptual development. International Journal of Retail \& Distribution Management, 38(11/12), 928-942.

- Alexander, N., \& Myers, H. (2000). The retail internationalisation process. International Marketing Review, 17(4/5), 334-353.

- Alexander, N., \& Quinn, B. (2002). International retail divestment. International Journal of Retail \& Distribution Management, 30(2), 112-125.

- Arrigo, E. (2015). The role of the flagship store location in luxury branding. An international exploratory study. International Journal of Retail and Distribution Management, 43(6), 518-537.

- Bhardwaj, V., Eickman, M., \& Runyan, R. C. (2011). A case study on the internationalization process of a "born-global" fashion retailer. The International Review of Retail, Distribution and Consumer Research, 21(3), 293-307.

- Bianchi, C. (2009). Retail internationalisation from emerging markets: case study evidence from Chile. International Marketing Review, 26(2), 221-243.

- Bianchi, C. (2011). The Growth and International Expansion of an Emerging Market Retailer in Latin America. Journal of Global Marketing, 24(4), 357-379.

- Bianchi, C., \& Arnold, S. J. (2004). An Institutional Perspective on Retail Internationalization Success: Home Depot in Chile. The International Review of Retail, Distribution and Consumer Research, 14(2), 149-169.

- Bianchi, C., \& Ostale, E. (2006). Lessons learned from unsuccessful internationalization attempts: Examples of multinational retailers in Chile. Journal of Business Research, 59(1), 140-147.

- Bonetti, F. (2014). Italian luxury fashion brands in China: a retail perspective. The International Review of Retail, Distribution and Consumer Research, 24(4), 453-477. 
- $\quad$ Burt, S., \& Mavrommatis, A. (2006). The international transfer of store brand image. The International Review of Retail, Distribution and Consumer Research, 16(4), 395-413.

- $\quad$ Burt, S., Mellahi, K., Jackson, T. P., \& Sparks, L. (2002). Retail internationalization and retail failure: issues from the case of Marks and Spencer. The International Review of Retail, Distribution and Consumer Research, 12(2), 191-219.

- Burt, S., \& Sparks, L. (2002). Corporate branding, retailing, and retail internationalization. Corporate Reputation Review, 5(2-3), 2-3.

- Cairns, P., Marie Doherty, A., Alexander, N., \& Quinn, B. (2008). Understanding the international retail divestment process. Journal of Strategic Marketing, 16(2), 111-128.

- Cairns, P., Quinn, B., Alexander, N., \& Doherty, A. M. (2010). The role of leadership in international retail divestment. European Business Review, 22(1), 25-42.

- Caniato, F., Caridi, M., Moretto, A., Sianesi, A., \& Spina, G. (2014). Integrating international fashion retail into new product development. International Journal of Production Economics, 147(PART B), 294-306.

- Carneiro, J., \& Dib, L. A. (2007). Avaliação Comparativa do Escopo Descritivo e Explanatório dos Principais Modelos de Internacionalização de Empresas. INTERNEXT - Revista Eletrônica de Negócios Internacionais da ESPM, 2(1), 1-25.

- Dawson, J. A. (1994). Internationalization of retailing operations. Journal of Marketing Management, 10(4), 267-282.

- Dawson, J. A. (2000). Retailing at century end: some challenges for management and research. The International Review of Retail, Distribution and Consumer Research, 10(2), 119-148.

- Delloite. (2014). Global Powers of Luxury 2015. Recuperado de http://www2.deloitte.com/global/en/pages/consumer -business/articles/gx-cb-global-powers-of-luxurygoods.html

- Diallo, M. F. (2012). Retailers' Internationalization in Emerging Markets: A Comparative Study of a French and a Local Retailer's Key Success Factors in Brazil. International Business Research, 5(10), 91-99.

- Doherty, A. M. (2007a). Support mechanisms in international retail franchise networks. International Journal of Retail \& Distribution Management, 35(10), 781-802.

- Doherty, A. M. (2007b). The internationalization of retailing: Factors influencing the choice of franchising as a market entry strategy. International Journal of Service Industry Management, 18(2), 184-205.

- Doherty, A. M. (2009). Market and partner selection processes in international retail franchising. Journal of Business Research, 62(5), 528-534.
- Doherty, A. M., \& Alexander, N. (2004). Relationship development in international retail franchising: Case study evidence from the UK fashion sector. European Journal of Marketing, 38(9/10), 1215-1235.

- Doherty, A. M., \& Alexander, N. (2006). Power and control in international retail franchising. European Journal of Marketing, 40(11/12), 1292-1316.

- Dunning, J. (1988). The eclectic paradigm of international production: a restatement and some possible extensions. Journal of International Business Studies, 19(1), 1-31.

- $\quad$ Elg, U., Ghauri, P. N., \& Tarnovskaya, V. (2008). The role of networks and matching in market entry to emerging retail markets. International Marketing Review, 25(6), 674-699.

- Eren-Erdogmus, I., Cobanoglu, E., Yalcin, M., \& Ghauri, P. N. (2010). Internationalization of emerging market firms: the case of Turkish retailers. International Marketing Review, 27(3), 316-337.

- Frasquet, M., Dawson, J. A., \& Mollá, A. (2013). Postentry internationalisation activity of retailers: An assessment of dynamic capabilities. Management Decision, 51(7), 1510-1527.

- Ghauri, P. N. (2004). Designing and Conducting Case Studies. In Handbook of Qualitative Research Methods for International Business (p. 109-124). Cheltenham, UK: Edward Elgar Publishing.

- Girod, S. J. G., \& Rugman, A. M. (2005). Regional Business Networks and the Multinational Retail Sector. Long Range Planning, 38(4), 335-357.

- Guercini, S., \& Runfola, A. (2010). Business networks and retail internationalization: A case analysis in the fashion industry. Industrial Marketing Management, 39(6), 908-916.

- Hernandez, T. (2003). The impact of big box internationalization on a national market: a case study of Home Depot Inc. in Canada. The International Review of Retail, Distribution and Consumer Research, 13(1), 77-98.

- Hutchinson, K., Alexander, N., Quinn, B., \& Doherty, A. M. (2007). Internationalization motives and facilitating factors: qualitative evidence from smaller specialist retailers. Journal of International Marketing, 15(3), 96122.

- Hutchinson, K., Fleck, E., \& Lloyd-Reason, L. (2009). An investigation into the initial barriers to internationalization: Evidence from small UK retailers. Journal of Small Business and Enterprise Development, 16(4), 544-568.

- Hutchinson, K., \& Quinn, B. (2011). Identifying the characteristics of small specialist international retailers. European Business Review, 23(3), 314-327.

- Hutchinson, K., Quinn, B., \& Alexander, N. (2006). The role of management characteristics in the internationalisation of SMEs: Evidence from the UK 
retail sector. Journal of Small Business and Enterprise Development, 13(4), 513-534.

- Hutchinson, K., Quinn, B., Alexander, N., \& Doherty, A. M. (2009). Retailer internationalization: Overcoming barriers to expansion. International Review of Retail, Distribution and Consumer Research, 19(3), 251-272.

- Ilonen, L., Wren, J., Gabrielsson, M., \& Salimäki, M. (2011). The role of branded retail in manufacturers' international strategy. International Journal of Retail \& Distribution Management, 39(6), 414-433.

- Jackson, P., \& Sparks, L. (2005). Retail internationalisation: Marks and Spencer in Hong Kong. International Journal of Retail \& Distribution Management, 33(10), 766-783.

- Johanson, J., \& Vahlne, J.-E. (1977). The internationalization process of the firm-a model of knowledge development and increasing foreign market commitments. Journal of International Business Studies, 8(1), 23-32.

- Jones, G. (2003). Middle East expansion - the case of Debenhams. International Journal of Retail \& Distribution Management, 31(7), 359-364.

- Jonsson, A. (2008). A transnational perspective on knowledge sharing: lessons learned from IKEA's entry into Russia, China and Japan. The International Review of Retail, Distribution and Consumer Research, 18(1), 17-44.

- Jonsson, A., \& Elg, U. (2006). Knowledge and knowledge sharing in retail internationalization: IKEA's entry into Russia. The International Review of Retail, Distribution and Consumer Research, 16(02), 239-256.

- Jonsson, A., \& Foss, N. J. (2011). International expansion through flexible replication: Learning from the internationalization experience of IKEA. Journal of International Business Studies, 42(9), 1079-1102.

- Lopez, C., \& Fan, Y. (2009). Internationalisation of the Spanish fashion brand Zara. Journal of Fashion Marketing and Management, 13(2), 279-296.

- Moore, C., Birtwistle, G., \& Burt, S. (2004). Channel power, conflict and conflict resolution in international fashion retailing. European Journal of Marketing, 38(7), 749-769.

- Moore, M., Doherty, A. M., N. S. Alexander, \& J. Carpenter. (2010). International retail brand origin recognition. In 6th Thought Leaders International Conference on Brand Management. Lugano, Suíça

- Palmer, M. (2005). Retail multinational learning: a case study of Tesco. International Journal of Retail \& Distribution Management, 33(1), 23-48.

- Palmer, M., \& Owens, M. (2006). New directions for international retail joint venture research. International Review of Retail, Distribution and Consumer Research, 16(02), 159-179.

- Palmer, M., Owens, M., \& De Kervenoael, R. (2010). Paths of the least resistance: understanding how motives form in international retail joint venturing. The Service Industries Journal, 30(6), 965-989.

- Palmer, M., \& Quinn, B. (2007). The nature of international retail divestment: insights from Ahold. International Marketing Review, 24(1), 26-45.

- Picot-Coupey, K. (2006). Determinants of international retail operation mode choice: Towards a conceptual framework based on evidence from French specialised retail chains. The International Review of Retail, Distribution and Consumer Research, 16(2), 215-237.

- Picot-Coupey, K. (2014). The pop-up store as a foreign operation mode (FOM) for retailers. International Journal of Retail and Distribution Management, 42(7), 643-670.

- Piekkari, R., Welch, C., \& Paavilainen, E. (2009). The case study as disciplinary convention: evidence from international business journals. Organizational Research Methods, 12(3), 567-589.

- Rocha, A., \& Dib, L. A. (2002). The entry of Wal-Mart in Brazil and the competitive responses of multinational and domestic firms. International Journal of Retail \& Distribution Management, 30(1), 61-73.

- Rogers, H., Ghauri, P. N., \& George, K. L. (2005). The Impact of Market Orientation on the Internationalization of Retailing Firms: Tesco in Eastern Europe. The International Review of Retail, Distribution and Consumer Research, 15(1), 53-74.

- Salmon, W. J., \& Tordjman, A. (1989). The internationalisation of retailing. International Journal of Retail \& Distribution Management, 4(2), 3-16.

- Swoboda, B., Zentes, J., \& Elsner, S. (2009). Internationalisation of retail firms: state of the art after 20 years of research. Marketing: Journal of Research and Management, 5(2), 105-126.

- Tranfield, D. R., Denyer, D., \& Smart, P. (2003). Towards a methodology for developing evidence-informed management knowledge by means of systematic review. British journal of management, 14, 207-222.

- Treadgold, A. (1991). Dixons and Laura Ashley: different routes to international growth. International Journal of Retail \& Distribution Management, 19(4).

- Vida, I., \& Fairhurst, A. (1998). International expansion of retail firms: A theoretical approach for future investigations. Journal of Retailing and Consumer Services, 5(3), 143-151.

- Welch, C., Piekkari, R., Plakoyiannaki, E., \& PaavilainenMäntymäki, E. (2011). Theorising from case studies: Towards a pluralist future for international business research. Journal of International Business Studies, 42(5), 740-762.

- Wigley, S., \& Chiang, C. R. (2009). Retail internationalisation in practice: per una in the UK and Taiwan. International Journal of Retail \& Distribution Management, 37(3), 250-270.

- Wigley, S., Moore, C., \& Birtwistle, G. (2005). Product and brand: Critical success factors in the 
internationalisation of a fashion retailer. International Journal of Retail \& Distribution Management, 33(7), 531-544
- Wigley, S., \& Moore, C. M. (2007). The operationalisation of international fashion retailer success. Journal of Fashion Marketing and Management, 11(2), 281-296.

\section{Sobre os autores}

- Renata Maria de Almeida Bastos Gomes é Doutora em administração de empresas pela Pontifícia Universidade Católica do Rio de Janeiro (PUC-Rio), graduada em sistemas de informação e pósgraduada em marketing pela PUC-Rio. Tem experiência na área de administração, com ênfase em marketing, negócios internacionais e varejo e atuou nas áreas de comércio exterior, propaganda e shopping centers nos últimos 30 anos. E-mail: renatamariagomes@uol.com.br

- Jorge Manoel Teixeira Carneiro é Professor Associado de Estratégia e de Negócios Internacionais da FGV/Eaesp. Possui doutorado em Administração de Empresas pelo Coppead/UFRJ, com especialização em Negócios Internacionais. É mestre em Administração de Empresas pela Pontifícia Universidade Católica do Rio de Janeiro PUC-Rio, com especialização em Marketing, e bacharel em Engenharia Eletrônica pela mesma instituição.E-mail: jorgemtc@iag.puc-rio.br

- Clarice Secches Kogut é Doutoranda do departamento de negócios internacionais do COPPEAD/UFRJ, com mestrado em administração de empresas da Universidade de Columbia, Nova York (2006-formado com honras) e bacharel em administração de empresas pela EAESP/FGV (2001), além de CFA (Chartered Financial Analyst). Profissional de experiências em grandes empresas multinacionais do setor financeiro, consultoria estratégica e bens de consumo. Atualmente trabalha como pesquisadora acadêmica, professora e coordenadora assistente de um curso de pós-MBA na COPPEAD/UFRJ. E-mail: clarice.kogut@coppead.ufrj.br 


\title{
Case studies in the retailer internationalization: a literature review
}

\author{
Renata Maria de Almeida Bastos Gomes ${ }^{\mathrm{A}}$, \\ Jorge Manoel Teixeira Carneiro ${ }^{B}$, Clarice Secches Kogut $^{C}$
}

${ }^{A}$ Pontifícia Universidade Católica do Rio de Janeiro - Instituto de Administração e Gerência, PUC-Rio/IAG, Rio de Janeiro, RJ, Brasil

${ }^{\mathrm{B}}$ Fundação Getúlio Vargas/Escola de Administração de Empresas de São Paulo, FGV-SP/EAESP, São Paulo, SP, Brasil

${ }^{C}$ Universidade Federal do Rio de Janeiro - Instituto Coppead de Administração, UFRJ/Coppead, Rio de Janeiro, RJ, Brasil

\section{ARTICLE DETAILS}

Article history:

Received 2 October 2015

Accepted 20 January 2017

Available online in 30 April 2017

Double Blind Review System

\section{Scientific Editor}

Ilan Avrichir

\section{Keywords:}

Retail internationalization

Case Study

Literature Review

\begin{abstract}
Research on retail internationalization (RI) has undergone an intense development phase since the 1990s, dominated by quantitative research and based on the retail experience of large-scale retailers formats such as supermarkets. However, the internationalization of the retail sector has evolved into areas that existing models have not been able to explain, generating a demand for more thorough research. The result has been an increase of articles published since the early 2000s based on research of an exploratory and qualitative nature, such as case studies. In this article, main contributions are identified in $\mathrm{RI}$ arising from case studies resulting from the selection and analysis of 48 articles published in academic journals between 2000 and 2015. As a result, relevant findings on the steps of the RI process are presented, such as input modes for franchise, international divestment, and characteristics of the RI process of specific types of firms, such as fashion retailers and small- and medium-size retailers.
\end{abstract}

(c) 2017 Internext | ESPM. All rights reserved.

Para citar este artigo:

Gomes R. M. A. B., Carneiro, J. M. T., Kogut, C. S. (2017). Estudos de caso na internacionalização varejista: uma revisão de literatura. Internext - Revista Eletrônica de Negócios Internacionais, 12 (1), 16-32. DOI: 10.18568/1980-4865.12116-32

Para acessar este artigo: $h t t p: / / d x . d o i . o r g / 10.18568 / 1980-4865.12116-32$ 